\title{
Unusual Glycemic Presentations in a Child with a Novel Heterozygous Intragenic INSR Deletion
}

\author{
Federica Verdecchia ${ }^{a} \quad$ Nese Akcan ${ }^{a} \quad$ Antonia Dastamani ${ }^{a} \quad K^{2}$ Morgan ${ }^{a}$ \\ Robert K. Semple ${ }^{b}$ Pratik Shah ${ }^{a, c}$ \\ aEndocrinology Department, Great Ormond Street Hospital for Children, NHS Foundation Trust, London, UK; \\ ${ }^{b}$ Centre for Cardiovascular Science, The Queen's Medical Research Institute, University of Edinburgh, Edinburgh, \\ UK; ' ${ }^{C}$ enetics and Epigenetics in Health and Disease Section, Genetics and Genomics Medicine Program, UCL GOS \\ Institute of Child Health, London, UK
}

\section{Established Facts}

- Mutations/deletions in the insulin receptor gene cause a wide spectrum of congenital disorders characterized by extreme insulin resistance (IR).

- Although type A-IR is congenital, it most commonly presents to medical attention peri-pubertally in girls with features of androgen excess such as oligomenorrhea or primary amenorrhea.

\section{Novel Insights}

- This case with a novel heterozygous insulin receptor (INSR) gene deletion exhibited unusual glycemic patterns that led to medical evaluation and diagnosis at a much earlier age than most other cases of type A insulin resistance.

- Early age manifestations of glycemic dysregulation such as neonatal hyperglycemia and/or postprandial hyperinsulinemic hypoglycemia should prompt consideration of genetic testing of INSR.

\section{Keywords}

Hyperinsulism · Hypoglycemia $\cdot$ INSR gene $\cdot$ Neonatal diabetes · Insulin resistance · Type A-IR

\section{Abstract \\ Background: Mutations of the insulin receptor (INSR) gene lead to a wide spectrum of inherited insulin resistance (IR) syndromes. Among these, type A-IR, usually caused by dominant negative INSR mutations, generally presents}

karger@karger.com www.karger.com/hrp

Karger $\stackrel{\text { ' }}{5}$ BOPEN ACCESS
(C) 2020 The Author(s)

Published by S. Karger AG, Basel

This article is licensed under the Creative Commons Attribution 4.0 International License (CC BY) (http://www.karger.com/Services/ OpenAccessLicense). Usage, derivative works and distribution are permitted provided that proper credit is given to the author and the original publisher. peri-pubertally in girls. Case: A 2.8-year-old girl was referred due to recurrent postprandial and fasting hypoglycemia. She had been born at full-term with birth weight $1.89 \mathrm{~kg}$, and had developed transient neonatal diabetes. Examination showed satisfactory growth, reduced adipose tissue, acanthosis nigricans, and isolated thelarche. After $12 \mathrm{~h}$ of fasting, she developed hypoglycemia (glucose 2.8

Pratik Shah

The Royal London Children's Hospital and Queen Mary University of London Barts Health NHS Trust

Whitechapel Road, London E1 1 FR (UK)

pratik.shah6@ nhs.net

Robert Semple

Centre for Cardiovascular Science

Queen's Medical Research Institute, Edinburgh Bioquarter, 47 Little France Crescent

Edinburgh EH16 4TJ (UK)

rsemple@exseed.ed.ac.uk 
$\mathrm{mmol} / \mathrm{L})$, with inappropriately raised plasma insulin concentration of $5.4 \mathrm{mU} / \mathrm{L}$ and suppressed fatty acids and ketone bodies. Oral glucose tolerance testing showed severely increased plasma insulin concentration ( $>300 \mathrm{mU} / \mathrm{L}$ ) with hypoglycemia (glucose $1.6 \mathrm{mmol} / \mathrm{L}$ ) at $2.5 \mathrm{~h}$. She was initially managed on dietary modifications, cornstarch, and then trialed on acarbose for postprandial hyperinsulinemic hypoglycemia (PPHH) with some response. However, she was noted to have increased frequency of hyperglycemia after a couple of years of treatment. She was then switched to metformin and continued to have dietary carbohydrate modification including cornstarch that improved fasting tolerance, hyperglycemia, and postprandial hypoglycemia. Genetic testing identified heterozygous deletion of the last exon of the INSR gene, exon 22. Conclusion: We present a case of type A-IR, caused by a novel INSR deletion, presenting unusually early with transient neonatal diabetes, followed by episodes of hypoglycemia and hyperglycemia during later childhood. Early life presentations, including neonatal diabetes and $\mathrm{PPHH}$, should lead to consideration of type A-IR.

(C) 2020 The Author(s)

Published by S. Karger AG, Basel

\section{Introduction}

Insulin signaling is critical for control of glucose metabolism and growth during the fetal period as well as in postnatal life [1]. The insulin receptor is a plasma membrane-associated receptor tyrosine kinase which functions as a dimer. Each monomer is composed of an $\alpha$ and a $\beta$-subunit which are encoded by a single gene on chromosome 19 composed of 22 exons. Mutations in the insulin receptor (INSR) gene cause a wide spectrum of congenital diseases featuring insulin resistance (IR). These include the severe, rare recessive disorders Donohue syndrome (DS) and Rabson-Mendenhall syndrome (RMS), and the more common type A-AR syndrome. Type A-IR is usually autosomal dominant, most commonly caused by a heterozygous dominant negative INSR mutation lying in the $\beta$-subunit [2-7]. While IR in the type A syndrome is congenital, it most commonly presents to medical attention peri-pubertally in girls, often due to oligomenorrhea or primary amenorrhea with features of androgen excess. Here, we report a patient with a precocious clinical presentation of type A-IR due to a novel INSR mutation. This included transient neonatal diabetes followed by episodes of hypoglycemia and hyperglycemia during childhood.

Pediatric Case with a Novel INSR

Mutation

\section{Case Presentation}

A 2.8-year-old girl was referred to a specialist center for evaluation due to episodes of postprandial and fasting hypoglycemia. She was born to non-consanguineous, healthy Afro-Caribbean parents after a pregnancy complicated by intrauterine growth retardation, with a birth weight of $1.89 \mathrm{~kg}$ ( -2.9 SDS). There was no family history of endocrinopathies or other relevant medical problems. She was reported to have transient neonatal hyperglycemia (blood glucose up to $15 \mathrm{mmol} / \mathrm{L}$ ) which resolved at 3 weeks of age. At 2.8 years of age, she was referred to a center for unexplained episodes of hypoglycemia as she presented with being tired and lethargic. On examination, her growth was satisfactory (weight: $14.3 \mathrm{~kg}$, standard deviation score [SDS: 0.53]; height: $97.4 \mathrm{~cm}$ [SDS: 1.96]), but acanthosis nigricans of the neck, a paucity of adipose tissue, and bilateral thelarche (B2, A1, P1, M0) were also noted. Thelarche had been present for more than 9 months without progression. No clitoromegaly, pubic hair, or adult body odor were detected. Her abdomen was soft without hepatosplenomegaly. Her skin was dry. GnRH test showed FSH predominance (Table 1), but did not demonstrate precocious puberty requiring intervention. Ultrasonography of abdomen and pelvis was normal.

Further investigations showed hyperinsulinemic hypoglycemia after a 12 -h fast (glucose $2.8 \mathrm{mmol} / \mathrm{L}$ with inappropriately raised insulin level of $5.4 \mathrm{mU} / \mathrm{L}$ ), with concomitantly suppressed plasma fatty acids and ketone bodies. Oral glucose tolerance testing (OGTT) (Table 2) showed severe hyperinsulinemia throughout the test $(>300 \mathrm{mU} / \mathrm{L}$ ) along with hypoglycemia (glucose 1.6 $\mathrm{mmol} / \mathrm{L}$ ) at $2.5 \mathrm{~h}$. Other results did not indicate further pituitary or metabolic deficits (Table 1). She was discharged home with diet modification.

At 5.1 years, acarbose was trialed, and she had mixed meal test (pre and post-acarbose) demonstrating some response (Table 3). During the test without acarbose, a rise in blood glucose to $9.7 \mathrm{mmol} / \mathrm{L}$ (at $90 \mathrm{~min}$ post meal) was seen, with plasma insulin concentration more than $300 \mathrm{mU} / \mathrm{L}$ at $60 \mathrm{~min}$. When the test was repeated on acarbose $12.5 \mathrm{mg}$ taken pre-meals, the glucose profile revealed neither hypoglycemia nor hyperglycemia despite continued severe elevation of plasma insulin ( $>300$ $\mathrm{mU} / \mathrm{L}$ at $30 \mathrm{~min}$ ). Acarbose, $12.5 \mathrm{mg} 3$ times a day, was thus started to prevent postprandial hypoglycemia, and was well tolerated with no side effects. Two years later, however, still on acarbose, the glucose profile recorded by continuous glucose monitoring showed intermittent episodes of hyperglycemia (up to $19.9 \mathrm{mmol} / \mathrm{L}$ ) along with postprandial and fasting hypoglycemia (nadir $2.2 \mathrm{mmol} / \mathrm{L}$ ) (Fig. 1). Acarbose was stopped and metformin was started (125 mg twice a day) along with a reduced carbohydrate diet supplemented with corn-starch (10 g once a day).

On final assessment at 8 years 6 months, the patient weighed $25.7 \mathrm{~kg}(-0.48 \mathrm{SDS})$, and her height was $130.9 \mathrm{~cm}$ (+0.35 SDS). She was prepubertal. Her HbAlc remained within the normal range on metformin (500 $\mathrm{mg}$ twice a day), dietary carbohydrate modification, and cornstarch. She had experienced only occasional hypoglycemic as well as hyperglycemic episodes (maximum peaking at $12-13 \mathrm{mmol} / \mathrm{L}$ ) once every $2-3$ weeks on this regimen. Retinal appearances and echocardiography were normal at this stage. 
Table 1. Clinical and Laboratory summary of the case

\begin{tabular}{|c|c|}
\hline \multicolumn{2}{|l|}{ On admision } \\
\hline Age, years & 2 years and 8 months \\
\hline Sex & Female \\
\hline Phenotype & $\begin{array}{l}\text { Acanthosis nigricans of neck, bilateral mild breast } \\
\text { development (B2), no pubic hair, and no clitoromegaly }\end{array}$ \\
\hline \multicolumn{2}{|r|}{ 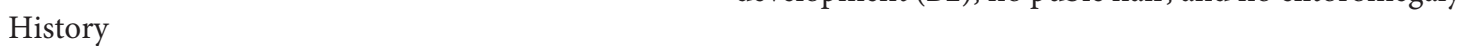 } \\
\hline Gestational age & Term \\
\hline Birth weight & $1.89 \mathrm{~kg}$ \\
\hline Family history & No endocrinopathies \\
\hline \multicolumn{2}{|l|}{ Laboratory } \\
\hline $\mathrm{HbA1c}(20-42), \mathrm{nmol} / \mathrm{L}$ & 34 \\
\hline Fasting glucose, (fasted for $8 \mathrm{~h}$ ), $\mathrm{mmol} / \mathrm{L}$ & 2.4 \\
\hline Insulin (mU/L) & $>300$ \\
\hline C-peptide, $\mathrm{pmol} / \mathrm{L}$ & 252 \\
\hline GnRH test - peak LH, IU/L & 2.1 \\
\hline GnRH test - peak FSH, IU/L & 19.9 \\
\hline Estradiol, $\mathrm{pmol} / \mathrm{L}$ & $<44$ \\
\hline GAD antibodies & Negative \\
\hline $\mathrm{NEFA}, \mathrm{mmol} / \mathrm{L}$ & 0.64 \\
\hline B-hydroxybutyrate, mmol/L & 0.05 \\
\hline $25 \mathrm{OH}$ vitamin $\mathrm{D}, \mathrm{nm} / \mathrm{L}(>50)$ & 21 \\
\hline \multicolumn{2}{|l|}{ Genetic analysis } \\
\hline INSR gene & Heterozygous deletion of exon 22 \\
\hline
\end{tabular}

Normal thyroid function test, cortisol, ammonia, lactate, plasma amino acids, urine organic acids, acylcarnitine profile. INSR, insulin receptor.

Table 2. OGTT results

\begin{tabular}{lllllll}
\hline At the age of 2 years and 8 months \\
\hline Time, min & 0 & 30 & 60 & 90 & 120 & 150 \\
Blood glucose, $\mathrm{mmol} / \mathrm{L}$ & 3.7 & 9.2 & 11.9 & 6.5 & 5.7 & 1.6 \\
Insulin, $\mathrm{mU} / \mathrm{L}$ & 19.9 & $>300$ & $>300$ & $>300$ & $>300$ & 225
\end{tabular}

OGTT, Oral glucose tolerance test.

\section{Molecular Analyses}

Written informed consent was obtained from the patient's legal guardians. Initial genetic analysis undertaken in the newborn period focused on neonatal diabetes; however, no mutations in the inwardly rectifying potassium channel subfamily J member 11 (KCNJ11), ATPbinding cassette subfamily $\mathrm{C}$ member $8(A B C C 8)$ were found, while microarray and TNDM 6q methylation analysis was normal. Transient neonatal diabetes with
Table 3. Mixed meal test with and without acarbose at age 5 years and 1 month

\begin{tabular}{|c|c|c|c|c|c|c|}
\hline \multicolumn{7}{|c|}{ Mixed meal test without acarbose } \\
\hline Time & $13: 00$ & $13: 30$ & $14: 00$ & $14: 30$ & $15: 00$ & $15: 30$ \\
\hline Glucose, $\mathrm{mmol} / \mathrm{L}$ & 3.0 & 3.2 & 5.7 & 6.9 & 8.8 & 6.5 \\
\hline Insulin, mU/L & 9.6 & 9.6 & 257 & $>300$ & $>300$ & $>300$ \\
\hline \multicolumn{7}{|c|}{$\begin{array}{l}\text { Mixed meal test with acarbose }(12.5 \mathrm{mg} \text { ) taken pre-meals (meals: } \\
5 \text { p.m. and 8:30 a.m.) }\end{array}$} \\
\hline Time & $08: 15$ & $08: 45$ & 09:15 & $09: 45$ & $10: 15$ & $10: 45$ \\
\hline Glucose, $\mathrm{mmol} / \mathrm{L}$ & 3.9 & 3.7 & 5.0 & 5.7 & 5.3 & 4.0 \\
\hline Insulin, $\mathrm{mU} / \mathrm{L}$ & 59.1 & 61.0 & $>300$ & $>300$ & $>300$ & $>300$ \\
\hline
\end{tabular}

negative genetic testing was thus diagnosed. Further molecular genetic testing focused on postprandial hyperinsulinemic hypoglycemia/IR. Sequencing of the INSR and PIK3R1 genes, both of which have been associated with severe IR and low birth weight was normal; however, on multiplex ligation-dependent probe amplification (MLPA) analysis, heterozygous deletion of exon 22 of the INSR gene was detected.

Exon 22 is the final exon of the INSR gene, and encodes the terminal 117 amino acids of the intracellular beta sub- 


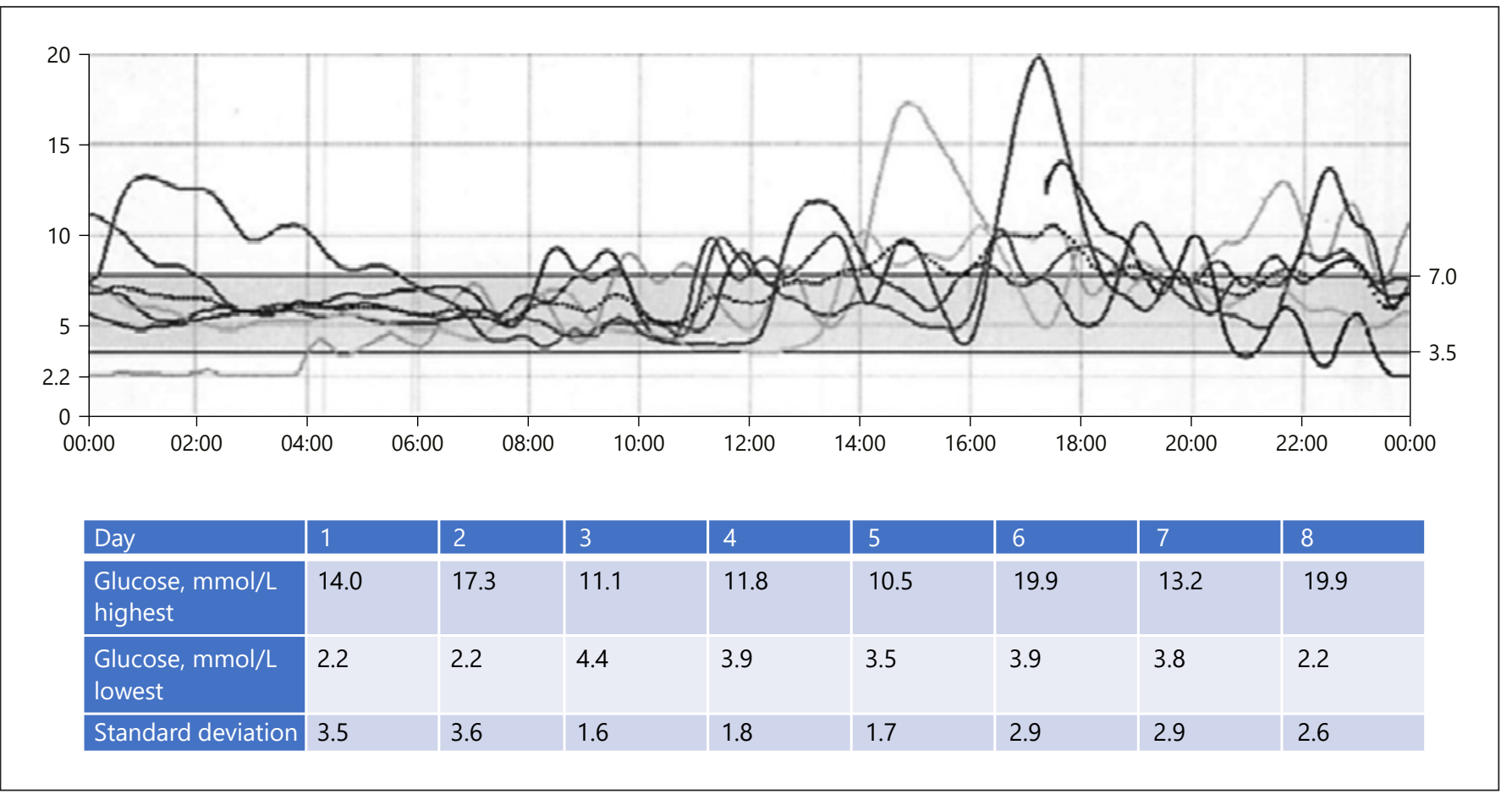

Fig. 1. Continuous glucose monitoring (with acarbose) for 7 days by Medtronic iPro2 Recorder.

unit of the receptor. Its loss would disrupt or remove the final 3 helices of the critical tyrosine kinase domain of the receptor as well as the $\mathrm{C}$ terminal domain of the beta subunit but would leave critical catalytic and nucleotidebinding residues in place [8]. The precise predicted protein product is not defined by the MLPA analysis, however. Neither parent was available to study. This deletion has not previously been reported but is highly likely to be pathogenic and causally associated with severe IR, like other loss of function mutations in the intracellular receptor. Therefore, this finding is possibly consistent with a diagnosis of type A severe IR.

\section{Discussion}

Type A-IR is characterized by severe IR, with the major features of the condition usually becoming clinically apparent in adolescence. Transient neonatal hyperglycemia with postprandial and fasting hypoglycemia in infancy and childhood have not been reported. This report thus features unusually early clinical presentation of type A-IR with a novel INSR mutation, illustrating a range of different glycemic presentations of severe IR and demonstrating how it can masquerade as other glycemic disorders. A possible reason for this manifestation could be the difference in INSR action at different stages of life. IR can escape diagnosis for many years due to compensatory hypersecretion by the beta-cell that maintains glycemic homeostasis. Hyperglycemia is often a late manifestation of IR, long preceded by episodes of serious symptomatic hypoglycemia prevalent after meals. The gradual decrease in pancreatic secretion leads initially to reduced carbohydrate tolerance and finally results in the development of diabetes.

More than 150 INSR gene mutations that cause a spectrum of IR syndromes are known $[9,10]$. Mutations associated with Donohue syndrome and Rabson-Mendenhall syndrome are present in both copies of the gene. These syndromes cause more severe IR than type 1-IR, as they present in infancy and are compatible with survival up to 2 years of age and puberty or early twenties, respectively [2-7]. Most INSR gene mutations that cause type A-IR are heterozygous and in the $\beta$ subunit and cause IR that becomes apparent around puberty or later $[4,5]$. The case we describe had a heterozygous deletion of exon 22 of the INSR gene, detected only by MLPA, which is undetected by conventional sequencing alone. The precise consequences of loss of exon 22 have not been studied, but it is likely to lead to truncation of the beta subunit with an aberrant $\mathrm{C}$ terminal tail. Much of the critical ty- 
rosine kinase domain, including nucleotide binding domain, activation loop and catalytic triad are left intact, and it is conceivable that the resulting dominant negative allele has different properties to the commoner pathogenic alleles with mutations earlier in the sequence, explaining the unusually early clinical presentation; however, this remains to be studied. Interestingly, another mutation also lying distal in the tyrosine kinase domain - p. Phe1213Leu - was recently described in association with another case that presented early with hypoglycemia [11]. Importantly, we were unable to test either parent, so could not establish if the mutation is de novo or carried by one of them. It is not uncommon for fathers, in particular, to be diagnosed with previously undetected severe IR after identification of severe IR in an affected daughter, reflecting some variable penetrance of mutations, and greater clinical expressivity in females.

Clinical abnormalities in this case were first observable in the intrauterine period, with low birth weight. Postnatally, a range of different dysglycemic features were seen during the neonatal period and infancy. There are no curative treatments available for IR, making management challenging. Acarbose, an alpha-glucosidases inhibitor, retards carbohydrate absorption, reducing postprandial glycemic peaks and insulin responses, with improvement of peripheral insulin sensitivity and/or optimization of pancreatic $\beta$-cell responsiveness also described [12]. A low glycemic index diet and acarbose have been reported to be helpful in type A-IR [9]. Initial therapy with acarbose in the current case helped to control postprandial hyperglycemia initially, but this was not sustained. Metformin, carbohydrate diet modification, and cornstarch provided adequate control; however, once hyperglycemia had supervened. Use of pharmacotherapy (metformin) and dietary modification including frequent meals as well as an increase in the protein content of evening feedings can help prevent fasting hypoglycemia.

Congenital IR, with a compensatory extreme hyperinsulinemia, has been associated with ovarian enlargement, ovarian cysts, and juvenile granulosa cell ovarian tumor, as well as secondary effects on sex hormone-dependent tissues including breast hyperplasia, prominent nipples, and clitoromegaly [12]. Our patient only exhibited isolated thelarche with FSH predominance on GnRH testing. This may be coincidental, but may also suggest a synergistic action between hyperinsulinemia and gonadotropins that may be more prominent during "minipuberty," before physiological suppression of gonadotropins occurs. No clitoromegaly was apparent and pelvic ultrasound was normal, and at the age of 8 years and 6 months, she was prepubertal. Despite early presentation of hyperinsulinemia with associated fasting hypoglycemia and postprandial hyperglycemia, her HbAlc remained normal during follow-up. Fasting lipids were in the normal range as expected in cases of INSR gene mutation [9].

\section{Conclusion}

Here, we present a novel heterozygous mutation in the INSR gene in a pediatric case of severe IR that presented unusually early with a range of different glycemic and growth manifestations of IR. Early-age manifestations such as neonatal diabetes and also postprandial hyperinsulinemic hypoglycemia should be considered as possible presentations of type A IR. Children with this disease can be challenging to manage using pharmacotherapy and dietary modification, balancing risks of hyperglycemia and hypoglycemia. Genetic testing for INSR mutation, and especially MLPA, should be used to ensure that whole exon deletions are ruled out. This type of test, and not only the sequencing, could be considered in children with history of growth retardation, hyperandrogenism along with history of hyperinsulinemic hypoglycemia (fasting or postprandial) along with phenotypic features like elfin face, gingival hyperplasia, acanthosis nigricans, and hypertrichosis. Further accumulation of genetically proven cases and long-term treatment outcomes following early diagnosis are required to understand the dynamics of this disease.

\section{Acknowledgement}

The authors wish to express their gratitude to the family who participated in this study.

\section{Statement of Ethics}

The patient's guardian provided written consent for publication of the submitted article, and the results of the accompanying genetic analyses, after a full explanation of the purpose and nature of all the procedures used.

\section{Conflicts of Interest Statement}

The authors have no conflicts of interest to disclose. 


\section{Funding Sources}

R.K.S. is funded by the Wellcome Trust (Grant No. 210752/Z/18/Z).

\section{References}

1 Hubbard SR. The insulin receptor: both a prototypical and atypical receptor tyrosine kinase. Cold Spring Harb Perspect Biol. 2013 Mar 1;5(3):a008946.

2 Longo N, Wang Y, Smith SA, Langley SD, DiMeglio LA, Giannella-Neto D. Genotypephenotype correlation in inherited severe insulin resistance. Hum Mol Genet. 2002 Jun 1; 11(12):1465-75.

3 Semple RK, Savage DB, Brierley GV, O’Rahilly S. Syndromes of severe insulin resistance and/ or lipodystrophy. In: Weiss RE, Refetoff S, editors. Genetic diagnosis of endocrine disorders. 2nd ed. Elsevier; 2015.

4 Semple RK, Savage DB, Cochran EK, Gorden P, O'Rahilly S. Genetic syndromes of severe insulin resistance. Endocr Rev. 2011;32(4): 498-514.

5 Hegele RA. Monogenic forms of insulin resistance: apertures that expose the common metabolic syndrome. Trends Endocrinol Metab 2003;14(8):371-7

\section{Author Contributions}

F.V. and N.A.: following-up the patient, clinical diagnosis, data collection, writing main draft of the article. R.K.S.: genetic analyses and reviewing and editing of manuscript. A.D., K.M., and P.S.: following-up the patient, clinical diagnosis, and writing and checking all the data in the article.
6 Grasso V, Colombo C, Favalli V, Galderisi A, Rabbone I, Gombos S, et al. Six cases with severe insulin resistance (SIR) associated with mutations of insulin receptor: is a bartter-like syndrome a feature of congenital SIR? Acta Diabetol. 2013 Dec;50(6):951-7.

7 Maassen JA, Tobias ES, Kayserilli H, Tukel T, Yuksel-Apak M, D'Haens E, et al. Identification and functional assessment of novel and known insulin receptor mutations in five patients with syndromes of severe insulin resistance. J Clin Endocrinol Metab. 2003 Sep; 88(9):4251-7.

8 Hubbard SR. Crystal structure of the activated insulin receptor tyrosine kinase in complex with peptide substrate and ATP analog. EMBO J. 1997 Sep 15;16(18):5572-81.
9 Parker VE, Semple RK Genetics in endocrinology: genetic forms of severe insulin resistance: what endocrinologists should know. Eur J Endocrinol. 2013 Oct;169(4):R71-80.

10 Kirel B, Bozdağ Ö, Köşger P, Aydoğdu SD, Alıncak E, Tekin N. A case of donohue syndrome "Leprechaunism" with a novel mutation in the insulin receptor gene. Turk Pediatri Ars. 2017;52(4):226-30.

11 Innaurato S, Brierley GV, Grasso V, Massimi A, Gaudino R, Sileno S, et al. Severe insulin resistance in disguise: a familial case of reactive hypoglycemia associated with a novel heterozygous INSR mutation. Pediatr Diabetes. 2018 Jun; 19(4):670-4.

12 H Delgado, T Lehmann, E Bobbioni-Harsch, J Ybarra, A Golay . Acarbose improves indirectly both insulin resistance and secretion in obese type 2 biabetic patients. Diabetes Metab. 2002;28(3):195-200. 